\section{Weekly weather cycles}

\section{E. N. Lawrence, Meteorological Office, Bracknell, Berkshire, England}

Dr. Munn, in his article on "urban meteorology" in the February issue, reports some early results from a study to determine whether there was a weekly cycle in Toronto weather. These results "indicate that there seems to be a weekly cycle at Toronto Bloor St" but "surprisingly, however, there is also a weekly cycle at the rural Beatrice location," which was presumably intended to be used in the analysis as a "control" station.

The question is "What is the explanation for the cycle at Beatrice?" Assuming that the results are significant, two possible causes come to mind: 1) the site at Beatrice could be affected by a very local feature such as a closeby wall of a house or nearby chimney and 2) the site may not be truly "rural."

A recent inspection report from Beatrice suggests that the site does not suffer from any such exposure defects and is not located amidst a collection of buildings that is large enough to produce a heat island, as found by Sharon and Koplowitz (Met. Rund., Heidelberg, 1972, p. 143). However, Beatrice may be situated in a region where distant urban and industrial sources produce a weekly variation in background air pollution: this weekly cycle could possibly be outof-phase, with a lag of a day or so.

Further investigations may support the suggestion implied here, that air pollution rather than other factors, such as thermal convection with cloud and/or rain, is the main cause of the weekly cycle, at least of temperature. However, weekly cycles may result from a combination of factors (Lawrence, 1971, Atmos. Environ., p. 935) and effective factors may operate to produce a complex weekly pattern rather than a simple single-wave cycle. It would seem that progress might be made from a study of other stations including at least one (say to the west of Beatrice) which is more likely to exhibit true rural characteristics, that is, the absence of a weekly cycle.
(Continued from announcements, page 1018)

\section{Weather and climate modification report}

A National Academy of Sciences panel has issued a report which finds both progress and problems in the field of weather modification. It has been established that cloud seeding can increase precipitation under some circumstances, and more detailed information has been gathered about what those circumstances are, but there is a serious lack of research funds and organizational force given weather modification by the federal government. In an attempt to amend this situation, the panel has proposed three national goals with a target date of 1980: 1) to put rainmaking and other precipitation modifications on a sound basis; 2) to develop methods to curtail the effects of the most severe storms and weather hazards; and 3) to determine the extent of inadvertent modification of local weather and the global climate by man-made pollutants.

The panel recommends the establishment of a national laboratory for weather modification, and research funding of $\$ 50$ million annually, despite the fact that federal spending in the field has been around $\$ 12$ million in recent years. Allen L. Hammond comments in the 17 August 1973 issue of Science that the panel did not attempt to tackle the difficult job of recommending which programs should have top priority if funds are limited.

Specific advances cited by the panel include the confirmation of the effectiveness of seeding orographic clouds. More than 14 years of randomized experiments near Climax, Colo., demonstrated that seeding clouds in which the temperature ranged between -11 and $-20 \mathrm{C}$ at the cloud tops could increase the snowfall in the region by 10 to $30 \%$. The results of seeding convective clouds are less certain. Questions have been raised about the downwind effects of cloud seeding and the panel recommends more serious study of this problem.

The results of attempts to modify weather hazards have been fairly unrewarding. Methods for dissipating warm fogs over airports or of reducing the intensity of tornadoes do not yet exist, and efforts to reduce forest fires caused by lightning are inconclusive. The prospect for preventing hailstorms is more hopeful, but a lack of statistical controls makes the experiments less convincing.

In regard to hurricane modification, the panel believes that randomization of seeding experiments on these storms is very important. It is agreed that predictions based on numerical models will be increasingly coupled with modification experiments.

In the area of inadvertent weather modification Hammond points out that the panel's report does not outline specific programs for monitoring pollutants. In regard to international policy the panel does cite with approval a proposed ban on military use of weather modification techniques.

The 1973 report, Weather and Climate Modification, Problems and Progress, T. F. Malone, Chairman, is available from the National Academy of Sciences, 2101 Constitution Ave., N.W., Washington, D.C., for $\$ 6.25$ (paperbound).

(More announcements on page 1050) 


BELFORT
MANUFACTURES
METEOROLOGICAL,
HYDROLOGICAL
AND
OCEANOGRAPHIC
INSTRUMENTS
Send for our free
catalog

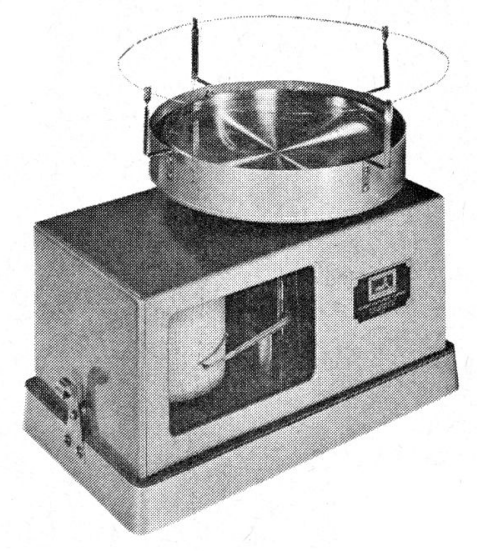

CAT. NO. 6075

RECORDING EVAPORATION GAUGE

Range: 0 to $20 \mathrm{~mm}$ of water column (0 to $20 \mathrm{~kg} / \mathrm{m}^{2}$ of water)

Accuracy: $\pm 0.2 \mathrm{~mm}$ of water column Weekly Chart-8 day chart drive

Price: $\$ 350.00$ FOB Baltimore

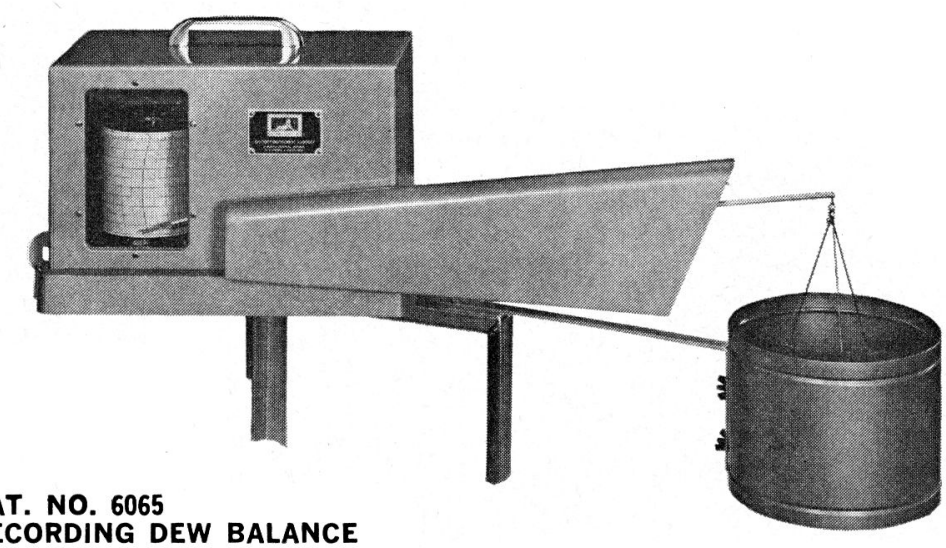

RECORDING DEW BALANCE

Range: 0 to 5.0 grams

Sensitivity: 0.05 grams

Weekly Chart-8 day chart drive

Price: $\$ 350.00$ FOB Baltimore

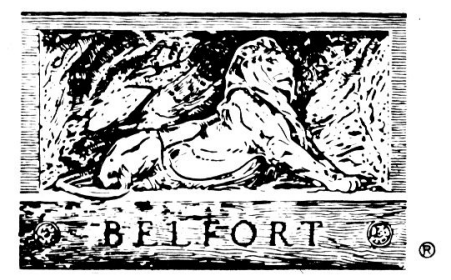

\section{BELFORT INSTRUMENT COMPANY}

1600 S. CLINTON STREET

BALTIMORE, MARYLAND 21224 U.S.A. 